\title{
Condition for existence of positive periodic solution of hepatitis B Virus infection model with immune response
}

\author{
Min Long, Tiejun Zhou ${ }^{*}$ \\ College of Science, Hunan Agricultural University, Changsha, Hunan 410128, China
}

Email address:

lonmy@qq.com (M. Long), hntjzhou@126.com (T. Zhou)

\section{To cite this article:}

Min Long, Tiejun Zhou. Condition for Existence of Positive Periodic Solution of Hepatitis B Virus Infection Model with Immune Response. Pure and Applied Mathematics Journal. Vol. 2, No. 2, 2013; pp. 106-109. doi: 10.11648/j.pamj.20130202.19

\begin{abstract}
In this paper, we consider a periodic Hepatitis B Virus infection model with immune response. By using continuation theorem of coincidence degree theory, a condition for the existence of positive periodic solution is obtained.
\end{abstract}

Keywords: Hepatitis B Virus Infection Model, Immune Response, Positive Periodic Solution, Coincidence Degree Theory

\section{Introduction}

Hepatitis B has become a worldwide disease [1]. When people are infected with $\mathrm{HBV}$, some antigens are secreted such as $\mathrm{HBsAg}, \mathrm{HBeAg}$ and $\mathrm{HBcAg}$. The virus antigens in blood or liver cell membrane can induce organism to produce the specific humoral and cellular immune response [2]. In recent years, research on Hepatitis B Virus model with immune response has been widely studied [3-9]. In [6], a Hepatitis B Virus infection model with the cellular immune and humoral immune was established as follows.

$$
\left\{\begin{array}{l}
y_{1}^{\prime}(t)=b-c y_{1}(t) y_{3}(t)-d y_{1}(t) \\
y_{2}^{\prime}(t)=b+c y_{1}(t) y_{3}(t)-m y_{2}(t) y_{4}(t)-d y_{2}(t), \\
y_{3}^{\prime}(t)=k y_{2}(t)-u y_{3}(t) y_{4}(t)-w y_{3}(t), \\
y_{4}^{\prime}(t)=s y_{3}(t) y_{4}(t)-h y_{4}(t)
\end{array}\right.
$$

where $\mathrm{y} 1(\mathrm{t}), \mathrm{y} 2(\mathrm{t}), \mathrm{y} 3(\mathrm{t})$ and $\mathrm{y} 4(\mathrm{t})$ denote density of uninfected liver cells, infected liver cells, free antigen in the blood and strength of immune response at time $t$, respectively. Here, the birth rate $b$ of uninfected cells is approximately equal to that of infected cells. The death rate per uninfected cell and per infected cell is a constant $d$. Uninfected cells are infected at rate cy1(t)y3(t). my2(t)y4(t) represents the removal rate of cellular immune response to infected liver cells. Antigens are produced by infected cells at rate $\mathrm{ky} 2(\mathrm{t})$, and die at rate $\mathrm{wy} 3(\mathrm{t})$. uy3 $(\mathrm{t}) \mathrm{y} 4(\mathrm{t})$ denotes the removal rate of the humoral immune response to antigens. sy $3(\mathrm{t}) \mathrm{y} 4(\mathrm{t})$ is the strength of specific immune response. Immune factors metabolic rate is hy4(t). In (1.1), the infection terms and immune responses are based on the mass-action principle. It is assumed that all parameters of system (1.1) are positive constants. By using Routh-Hurwitz criteria, Fang and Zhou studied the local asymptotic stability of a positive equilibrium point of system (1.1), and they also proved that the stable switch will occur with the delay increasing [6].

In fact, uninfected liver cells and infected liver cells are not generated at the same rate and they do not die also at the same rate. Because of the circadian rhythms of human body, the model parameters should depend on time and take place change periodically. Therefore, we establish the following model on the basis of the model (1.1).

$$
\left\{\begin{aligned}
y_{1}^{\prime}(t)= & b_{1}(t)-c(t) y_{1}(t) y_{3}(t)-d_{1}(t) y_{1}(t), \\
y_{2}^{\prime}(t)= & b_{2}(t)+c(t) y_{1}(t) y_{3}(t)-m(t) y_{2}(t) y_{4}(t) \\
& \quad-d_{2}(t) y_{2}(t), \\
y_{3}^{\prime}(t)= & k(t) y_{2}(t)-h(t) y_{3}(t) y_{4}(t)-d_{3}(t) y_{3}(t), \\
y_{4}^{\prime}(t)= & s(t) y_{3}(t) y_{4}(t)-d_{4}(t) y_{4}(t),
\end{aligned}\right.
$$

where $b_{1}(t), b_{2}(t), c(t), d_{1}(t), d_{2}(t), d_{3}(t), m(t), k(t), h(t), s(t)$ and $d_{4}(t)$ are positive continuous $T$-periodic functions. $b_{1}(t)$ and $b_{2}(t)$ are the birth rate of uninfected liver cells, infected liver cells, respectively. $d_{1}(t) y_{1}(t), d_{2}(t) y_{2}(t)$ and $d_{3}(t) y_{3}(t)$ are the death rate of uninfected liver cells, infected liver cells and antigen, respectively. Immune factors metabolic rate is $d_{4}(t) y_{4}(t) . h(t) y_{3}(t) y_{4}(t)$ denotes the removal rate of the humoral immune response to antigens. The meanings of other parameters are the same to (1.1). In order to understand the causes of the spontaneous fluctuation 
pattern of HBV DNA loads in chronically infected patients, we investigate the existence of a positive periodic solution of the hepatitis B virus infection model (1.2).

\section{Existence of Positive Periodic Solution}

First, we introduce some important concepts by Gain and Mawhin [10].

Let $X$ and $Z$ be real Banach spaces; $L: \operatorname{Dom}(L) \subset X \rightarrow Z$ be a linear mapping, and $N: X \rightarrow Z$ be a continuous mapping. The mapping $L$ is called a Fredholm mapping of index zero if $\operatorname{dim}(\operatorname{Ker}(L))=\operatorname{codim}(\operatorname{Im}(L))<+\infty$ and $\operatorname{Im}(L)$ is closed in $Z$. If $L$ is a Fredholm mapping of index zero, there exist continuous projectors $P: X \rightarrow X$ and $Q: Z \rightarrow Z$ such that $\operatorname{Im}(P)$ $=\operatorname{Ker}(L)$ and $\operatorname{Im}(L)=\operatorname{Ker}(Q)=\operatorname{Im}(I-Q)$. It follows that the restriction $L_{P}$ of $L$ to $\operatorname{Dom}(L) \cap \operatorname{Ker}(P)$ is invertible. We denote the inverse of this map $L_{P}$ by $K_{P}$. If $\Omega$ is an open bounded set of $X$, the mapping $N$ is called $L$-compact on $\bar{\Omega}$ if $Q N(\bar{\Omega})$ is bounded and $K_{P}(I-Q) N: \bar{\Omega} \rightarrow X$ is compact. Since $\operatorname{Im}(Q)$ is isomorphic to $\operatorname{Ker}(L)$, there exists an isomorphism $J: \operatorname{Im}(Q) \rightarrow \operatorname{Ker}(L)$.

Next, we introduce continuation theorem of Gaines and Mawhin [10].

Lemma 2.1 Let $L$ be a Fredholm mapping of index zero and let $N$ be $L$-compact on $\bar{\Omega}$. Suppose

(1) $L(x) \neq \lambda N(x), \forall \lambda \in(0,1), x \in \partial \Omega \cap \operatorname{Dom}(L)$;

(2) $Q N(x) \neq 0, \forall x \in \operatorname{Ker}(L) \cap \partial \Omega$;

(3) $\operatorname{deg}_{\mathrm{B}}(J Q N, \Omega \cap \operatorname{Ker}(L), 0) \neq 0$.

Then $L(x)=N(x)$ has at least one solution in $\operatorname{Dom}(L) \cap \bar{\Omega}$.

For convenience, we introduce some notations:

$$
f^{l}=\min _{t \in[0, T]} f(t), f^{M}=\max _{t \in[0, T]} f(t), \bar{f}=\frac{1}{T} \int_{0}^{T} f(t) d t
$$

where $f(t)$ is a continuous $T$-periodic function.

Theorem 2.1 If $d_{1}{ }^{l} d_{2}{ }^{l} d_{3}{ }^{l}-b_{1}{ }^{M} c^{M} k^{M}>0$, then system (1.2) has at least one positive $T$-periodic solution.

Proof Define four function as follows,

$$
\begin{gathered}
F_{1}(t)=b_{1}(t) \mathrm{e}^{-u_{1}(t)}-c(t) \mathrm{e}^{u_{3}(t)}-d_{1}(t), \\
F_{2}(t)=b_{2}(t) \mathrm{e}^{-u_{2}(t)}+c(t) \mathrm{e}^{u_{1}(t)+u_{3}(t)-u_{2}(t)}-m(t) \mathrm{e}^{u_{4}(t)}-d_{2}(t), \\
F_{3}(t)=k(t) \mathrm{e}^{u_{2}(t)-u_{3}(t)}-h(t) \mathrm{e}^{u_{4}(t)}-d_{3}(t), \\
F_{4}(t)=s(t) \mathrm{e}^{u_{3}(t)}-d_{4}(t) .
\end{gathered}
$$

Let $y i(t)=\exp (u i(t)), i=1,2,3,4$. Then system (1.2) is rewritten as

$$
u_{i}^{\prime}(t)=F_{i}(t), i=1,2,3,4
$$

To prove the existence of positive periodic solution system (1.2), we need to prove the existence of periodic solution of system (2.1). Let

$\mathrm{X}=\mathrm{Z}=\{(\mathrm{u} 1, \mathrm{u} 2, \mathrm{u} 3, \mathrm{u} 4) \mathrm{T} \in \mathrm{C}(\mathrm{R}, \mathrm{R} 4): \mathrm{ui}(\mathrm{t})=\mathrm{ui}(\mathrm{t}+\mathrm{T})$,

$$
\mathrm{i}=1,2,3,4\} \text {, }
$$

and define the norm of $X$ and $Z$

$$
\|u\|=\sum_{i=1}^{4} \max _{t \in[0, T]}\left|u_{i}(t)\right|, u \in X \quad \text { or } \quad u \in Z,
$$

then $X, Z$ are Banach spaces. Let

$$
\begin{gathered}
\mathrm{N}(\mathrm{u})=(\mathrm{F} 1(\mathrm{t}), \mathrm{F} 2(\mathrm{t}), \mathrm{F} 3(\mathrm{t}), \mathrm{F} 4(\mathrm{t})) \mathrm{T}, \\
L(u)=u^{\prime}, P(u)=\bar{u}, u \in X, Q(z)=\bar{z}, z \in Z,
\end{gathered}
$$

Thus, it follows that $\operatorname{Ker}(L)=\mathrm{R}^{4}$,

$$
\operatorname{Im}(L)=\left\{z \in Z: \int_{0}^{T} z_{i}(t) d t=0, i=1,2,3,4\right\}
$$

is closed in $Z, \operatorname{dim}(\operatorname{Ker}(L))=4=\operatorname{codim}(\operatorname{Im}(L))$ and $P, Q$ are continuous projectors such that $\operatorname{Im}(P)=\operatorname{Ker}(L), \operatorname{Ker}(Q)$ $=\operatorname{Im}(L)=\operatorname{Im}(I-Q)$. Hence, $L$ is a Fredholm mapping of index zero. Furthermore, the generalized inverse (to $L$ ) is

$$
\begin{gathered}
\mathrm{Kp}: \operatorname{Im}(\mathrm{L}) \rightarrow \operatorname{Ker}(\mathrm{P}) \cap \operatorname{Dom}(\mathrm{L}), \\
K_{P}(z)=\int_{0}^{t} z(s) d s-\frac{1}{T} \int_{0}^{T} \int_{0}^{t} z(s) d s d t .
\end{gathered}
$$

Thus,

$$
Q N(u)=\left(\bar{F}_{1}, \bar{F}_{2}, \bar{F}_{3}, \bar{F}_{4}\right)^{T}
$$

and

$$
\begin{aligned}
& K_{P}(I-Q) N(u)= \\
& \left(\begin{array}{l}
\int_{0}^{t} F_{1}(s) d s-\frac{1}{T} \int_{0}^{T} \int_{0}^{t} F_{1}(s) d s d t+\left(\frac{1}{2}-\frac{t}{T}\right) \int_{0}^{T} F_{1}(s) d s \\
\int_{0}^{t} F_{2}(s) d s-\frac{1}{T} \int_{0}^{T} \int_{0}^{t} F_{2}(s) d s d t+\left(\frac{1}{2}-\frac{t}{T}\right) \int_{0}^{T} F_{2}(s) d s \\
\int_{0}^{t} F_{3}(s) d s-\frac{1}{T} \int_{0}^{T} \int_{0}^{t} F_{3}(s) d s d t+\left(\frac{1}{2}-\frac{t}{T}\right) \int_{0}^{T} F_{3}(s) d s \\
\int_{0}^{t} F_{4}(s) d s-\frac{1}{T} \int_{0}^{T} \int_{0}^{t} F_{4}(s) d s d t+\left(\frac{1}{2}-\frac{t}{T}\right) \int_{0}^{T} F_{4}(s) d s
\end{array}\right) .
\end{aligned}
$$

Obviously, $Q N$ and $K_{P}(I-Q) N$ are continuous. By Arze la-Ascoli Theorem, we know that for any open bounded set $\Omega \subset X, K_{p}(I-Q) N(\bar{\Omega})$ is compact. Therefore, $N$ is $L$-compact on $\bar{\Omega}$ for open bounded set $\Omega \subset X$.

Corresponding to the operator equation $L(x)=\lambda N(x)$, $\lambda \in(0,1)$, we have

$$
u_{i}^{\prime}(t)=\lambda F_{i}(t), i=1,2,3,4
$$

where $\lambda \in(0,1)$. Assume that $u=u(t) \in X$ is a $T$-periodic solution of (2.2). There exist $\xi_{i}, \eta_{i} \in[0, T]$ such that 


$$
u_{i}\left(\xi_{i}\right)=\max _{t \in[0, T]} u_{i}(t), u_{i}\left(\eta_{i}\right)=\min _{t \in[0, T]} u_{i}(t), i=1,2,34 .
$$

Obviously, $u_{i}^{\prime}\left(\xi_{i}\right)=0, u_{i}^{\prime}\left(\eta_{i}\right)=0$ for $i=1,2,3$, 4. From

(2.2) we obtain $F_{i}\left(\xi_{i}\right)=0, F_{i}\left(\eta_{i}\right)=0$ for $i=1,2,3,4$.

From $F_{1}\left(\xi_{1}\right)=0$, we have

$$
b_{1}\left(\xi_{1}\right) e^{-u_{1}\left(\xi_{1}\right)}=c\left(\xi_{1}\right) e^{u_{3}\left(\xi_{1}\right)}+d_{1}\left(\xi_{1}\right)
$$

So $b_{1}^{M} \mathrm{e}^{-u_{1}\left(\xi_{1}\right)}>d_{1}^{l}$, that is

$$
\mathrm{e}^{u_{1}\left(\xi_{1}\right)}<\frac{b_{1}^{M}}{d_{1}^{l}}:=\delta_{1}
$$

The equality $F_{3}\left(\xi_{3}\right)=0$ can be rewritten as

$$
k\left(\xi_{3}\right) \mathrm{e}^{u_{2}\left(\xi_{3}\right)-u_{3}\left(\xi_{3}\right)}=h\left(\xi_{3}\right) \mathrm{e}^{u_{4}\left(\xi_{3}\right)}+d_{3}\left(\xi_{3}\right)
$$

Hence $k^{M} \mathrm{e}^{u_{2}\left(\xi_{3}\right)-u_{3}\left(\xi_{3}\right)}>d^{l}$, and then we obtain

$$
\mathrm{e}^{u_{3}\left(\xi_{3}\right)}<\frac{k^{M} \mathrm{e}^{u_{2}\left(\xi_{3}\right)}}{d_{3}^{l}}<\frac{k^{M} \mathrm{e}^{u_{2}\left(\xi_{2}\right)}}{d_{3}^{l}}
$$

The equality $F_{2}\left(\xi_{2}\right)=0$ implies

$$
b_{2}\left(\xi_{2}\right) \mathrm{e}^{-u_{2}\left(\xi_{2}\right)}+c(t) \mathrm{e}^{u_{1}\left(\xi_{2}\right)+u_{3}\left(\xi_{2}\right)-u_{2}\left(\xi_{2}\right)}=m\left(\xi_{2}\right) \mathrm{e}^{u_{4}\left(\xi_{2}\right)}+d_{2}\left(\xi_{2}\right)
$$

So we have

$$
d_{2}^{l}<b_{2}^{M} \mathrm{e}^{-u_{2}\left(\xi_{2}\right)}+c^{M} \mathrm{e}^{u_{1}\left(\xi_{1}\right)+u_{3}\left(\xi_{3}\right)-u_{2}\left(\xi_{2}\right)}
$$

According to (2.3), (2.4) and (2.5), we know

$$
d_{2}^{l}<b_{2}^{M} \mathrm{e}^{-u_{2}\left(\xi_{2}\right)}+\frac{c^{M} b_{1}^{M} k^{M}}{d_{1}^{l} d_{3}^{l}}
$$

that is

$$
\mathrm{e}^{u_{2}\left(\xi_{2}\right)}<\frac{b_{2}^{M} d_{1}^{l} d_{3}^{l}}{d_{1}^{l} d_{2}^{l} d_{3}^{l}-b_{1}^{M} c^{M} k^{M}}:=\delta_{2}
$$

From (2.4) and (2.6) we obtain

$$
\mathrm{e}^{u_{3}\left(\xi_{3}\right)}<\frac{b_{2}^{M} d_{1}^{l} k^{M}}{d_{1}^{l} d_{2}^{l} d_{3}^{l}-b_{1}^{M} c^{M} k^{M}}:=\delta_{3}
$$

Integrating the fourth equality of $(2.1)$ in $[0, T]$, we get

$$
\int_{0}^{T} s(t) \mathrm{e}^{u_{3}(t)} d t=\int_{0}^{T} d_{4}(t) d t=T \bar{d}_{4}
$$

Integrating the fourth equation of (2.1) in $[0, t]$ and taking the absolute value, from (2.8) we have

$$
\left|\int_{0}^{t} u_{4}^{\prime}(t) d t\right| \leq \int_{0}^{T}\left(s(t) \mathrm{e}^{u_{3}(t)}+d_{4}(t)\right) d t=2 T \bar{d}_{4} .
$$

Let $\delta_{4}=\left|u_{4}(0)\right|+2 T \bar{d}_{4}$, then we have

$$
-\delta_{4} \leq u_{4}(t) \leq \delta_{4}
$$

for any $t \in[0, T]$.

The equality $F_{1}\left(\eta_{1}\right)=0$ implies

$$
\begin{aligned}
b_{1}^{l} \mathrm{e}^{-u_{1}\left(\eta_{1}\right)} & \leq b_{1}\left(\eta_{1}\right) \mathrm{e}^{-u_{1}\left(\eta_{1}\right)}=c\left(\eta_{1}\right) \mathrm{e}^{u_{3}\left(\eta_{1}\right)}+d_{1}\left(\eta_{1}\right) \\
& <c^{M} \mathrm{e}^{u_{3}\left(\xi_{3}\right)}+d_{1}^{l}<c^{M} \delta_{3}+d_{1}^{l} .
\end{aligned}
$$

Therefore,

$$
\mathrm{e}^{u_{1}\left(\eta_{1}\right)}>\frac{b_{1}^{l}}{c^{M} \delta_{3}+d_{1}^{l}}:=\rho_{1}
$$

From $F_{2}\left(\eta_{2}\right)=0$ we have

$$
b_{2}\left(\eta_{2}\right) \mathrm{e}^{-u_{2}\left(\eta_{2}\right)}<m\left(\eta_{2}\right) \mathrm{e}^{u_{4}\left(\eta_{2}\right)}+d_{2}\left(\eta_{2}\right)<m^{M} \mathrm{e}^{u_{4}\left(\eta_{2}\right)}+d_{2}^{M} .
$$

According to (2.9), we have

$$
\mathrm{e}^{u_{2}\left(\eta_{2}\right)}>\frac{b_{2}^{l}}{m^{M} \mathrm{e}^{\delta_{4}}+d_{2}^{M}}:=\rho_{2}
$$

From $F_{3}\left(\eta_{3}\right)=0$ we have

$$
k\left(\eta_{3}\right) \mathrm{e}^{u_{2}\left(\eta_{3}\right)-u_{3}\left(\eta_{3}\right)}=h\left(\eta_{3}\right) \mathrm{e}^{u_{4}\left(\eta_{3}\right)}+d_{3}\left(\eta_{3}\right) .
$$

Thus we can obtain

$$
k^{l} \mathrm{e}^{u_{2}\left(\eta_{2}\right)-u_{3}\left(\eta_{3}\right)}<k\left(\eta_{3}\right) \mathrm{e}^{u_{2}\left(\eta_{3}\right)-u_{3}\left(\eta_{3}\right)}<h^{M} \mathrm{e}^{\delta_{4}}+d_{3}^{M}
$$

Therefore, we obtain

$$
\mathrm{e}^{u_{3}\left(\eta_{3}\right)}>\frac{k^{l} \mathrm{e}^{u_{2}\left(\eta_{2}\right)}}{h^{M} \mathrm{e}^{\delta_{4}}+d_{3}^{M}} .
$$

Therefore, from (2.11) we have

$$
\mathrm{e}^{u_{3}\left(\eta_{3}\right)}>\frac{k^{l} \rho_{2}}{h^{M} \mathrm{e}^{\delta_{4}}+d_{3}^{M}}:=\rho_{3} .
$$

Let

$$
H=\sum_{i=1}^{3} \max \left\{\left|\ln \rho_{i}\right|,\left|\ln \delta_{i}\right|\right\}+\delta_{4} .
$$

Obviously, $H$ is independent of $\lambda$. Now define

$$
\Omega=\left\{u=\left(u_{1}(t), u_{2}(t), u_{3}(t), u_{4}(t)\right)^{T} \in X:\|u\|<H\right\} .
$$

According to (2.3), (2.6), (2.7), (2.9), (2.10), (2.11) and (2.12), $\Omega$ satisfies the condition (1) in Lemma 2.1.

Next, we prove that $Q N(u) \neq 0$ for $u \in \partial \Omega \cap \operatorname{Ker}(L)$. Because $\operatorname{Ker}(L)=\mathrm{R}^{4}$, when $u \in \partial \Omega \cap \operatorname{Ker}(L), u=\left(u_{1}, u_{2}, u_{3}\right.$, $\left.u_{4}\right)^{T}$ is a constant vector, and $\|u\|=H$. Assume that $Q N(u)=0$, then 


$$
\begin{gathered}
\int_{0}^{T}\left(b_{1}(t) e^{-u_{1}}-c(t) e^{u_{3}}-d_{1}(t)\right) d t=0, \\
\int_{0}^{T}\left(b_{2}(t) \mathrm{e}^{-u_{2}}+c(t) \mathrm{e}^{u_{1}+u_{3}-u_{2}}-m(t) \mathrm{e}^{u_{4}}-d_{2}(t)\right) d t=0, \\
\int_{0}^{T}\left(k(t) \mathrm{e}^{u_{2}-u_{3}}-h(t) \mathrm{e}^{u_{4}}-d_{3}(t)\right) d t=0, \\
\int_{0}^{T}\left(s(t) \mathrm{e}^{u_{3}}-d_{4}(t)\right) d t=0 .
\end{gathered}
$$

That is

$$
\left\{\begin{array}{l}
\bar{b}_{1} \mathrm{e}^{-u_{1}}-\bar{c} \mathrm{e}^{u_{3}}-\bar{d}_{1}=0, \\
\bar{b}_{2} \mathrm{e}^{-u_{2}}+\bar{c} \mathrm{e}^{u_{1}+u_{3}-u_{2}}-\bar{m} \mathrm{e}^{u_{4}}-\bar{d}_{2}=0, \\
\bar{k} \mathrm{e}^{u_{2}-u_{3}}-\bar{h} \mathrm{e}^{u_{4}}-\bar{d}_{3}=0, \\
\bar{s} \mathrm{e}^{u_{3}}-\bar{d}_{4}=0 .
\end{array}\right.
$$

Similar to the proof process of (2.3), (2.6), (2.7), (2.9), (2.10), (2.11) and (2.12), the equation (2.13) implies $\|u\|<H$, that is $u \in \Omega$, it contradicts in $u \in \partial \Omega \cap \operatorname{Ker}(L)$. Therefore, the condition (2) in Lemma 2.1 holds.

We show that the condition (3) in Lemma 2.1 also holds. Consider the following system:

$$
\left\{\begin{array}{l}
\frac{\bar{b}_{1}}{x_{1}}-\bar{c} x_{3}-\bar{d}_{1}=0 \\
\frac{\bar{b}_{2}}{x_{2}}+\frac{\bar{c} x_{1} x_{3}}{x_{2}}-\bar{m} x_{4}-\bar{d}_{2}=0 \\
\frac{\bar{k} x_{2}}{x_{3}}-\bar{h} x_{4}-\bar{d}_{3}=0 \\
\overline{s x_{3}}-\bar{d}_{4}=0
\end{array}\right.
$$

The equation (2.14) has distinct solution $\left(x_{1}{ }^{*}, x_{2}{ }^{*}, x_{3}{ }^{*}, x_{4}{ }^{*}\right)$, where

$$
\begin{gathered}
x_{1}^{*}=\frac{\bar{b}_{1} \bar{s}}{c \bar{d} \bar{d}_{4}+\bar{s}_{1}}, \quad x_{2}^{*}=\frac{\bar{h} \bar{d}_{4} x_{4}+\bar{d}_{3} \bar{d}_{4}}{\overline{k s}}, \\
x_{3}^{*}=\frac{\bar{d}_{4}}{\bar{s}}, \quad x_{4}^{*}=\frac{\bar{k} x_{2}^{*}}{\bar{h} x_{3}^{*}}-\frac{\overline{d_{3}}}{\bar{h}} .
\end{gathered}
$$

Because $\operatorname{Im}(Q)=\operatorname{Ker}(L)$, we can take $J=I$. A direct computation gives

$$
\operatorname{deg}_{B}\left\{J Q N, \Omega \cap \operatorname{Ker}(L),(0,0,0,0)^{T}\right\}
$$

$$
\begin{aligned}
& =\operatorname{sign}\left|\begin{array}{cccc}
-\frac{\bar{b}_{1}}{\left(x_{1}^{*}\right)^{2}} & 0 & -\bar{c} & 0 \\
\frac{\bar{c} x_{3}^{*}}{x_{2}^{*}} & -\frac{\bar{b}_{2}}{\left(x_{2}^{*}\right)^{2}}-\frac{\bar{c} x_{1}^{*} x_{3}^{*}}{\left(x_{2}^{*}\right)^{2}} & \frac{\bar{c} x_{1}^{*}}{x_{2}^{*}} & -\bar{m} \\
0 & \frac{\bar{k}}{x_{3}^{*}} & -\frac{\bar{k} x_{2}^{*}}{\left(x_{3}^{*}\right)^{2}} & -\bar{h} \\
0 & 0 & \bar{s} & 0
\end{array}\right| \\
& =\operatorname{sign}\left|-\frac{\bar{b}_{1} \bar{s}}{\left(x_{1}^{*}\right)^{2}}\left(\frac{\bar{b}_{2} \bar{h}+\bar{c}_{1}^{*} x_{3}^{*}}{\left(x_{2}^{*}\right)^{2}}+\frac{\bar{m} \bar{k}}{x_{3}^{*}}\right)\right|=-1 \neq 0 .
\end{aligned}
$$

Therefore, the condition (3) in Lemma 2.1 is satisfied.

By Lemma 2.1, the system (2.1) has at least one $T$-periodic solution. Therefore system (1.2) has at least one positive $T$-periodic solution.

\section{Conclusion}

This paper considers a hepatitis B virus infection model with the immune response. By using the coincidence degree theory, we obtain a condition that ensures the existence of one positive periodic solution of this system. If the system (1.2) has a positive periodic solution, then it shows that the hepatitis B viruses are not cleared fully in some cases. This result can be used to explain the wave phenomena of hepatitis B virus in patients. It also can be used to guide the clinical treatment. From the condition of Theorem 2.1, we know that the therapeutic measures should be taken to reduce the mortalities of uninfected liver cells, infected liver cells and free antigen in the blood, to increase the uninfected liver cell birth rate.

This work was supported by the project of Hunan Provincial Department of Finance ([2010]51).

\section{References}

[1] D. Lavanchy, "Hepatitis B virus epidemiology, disease burden, treatment, and current and emerging prevention and control measures," J. Viral Hepat, vol.11, pp. 97-107, Sept. 2004.

[2] A.F. Lok, B.J. Mcmahon, "Chronic hepatitis B: Update 2009”, Hepatology, vol. 50, pp.661-662, 2009.

[3] A. Murase, T. Sasaki, T. Kajiwara, "Stability analysis of pathogen-immune interaction dynamics," J. Math. Biol., vol.51, pp. 247-267, Sept. 2005.

[4] M. A. Nowak, C.R.M. Bangham, "Population Dynamics of Immune Responses to Persistent Viruses," Science, vol.272, pp.74-79, Apr. 1996.

[5] S. M. Ciupe, R. M. Ribeiro, P. W. Nelson, A. S. Perelson, "Modeling the mechanisms of acute hepatitis B virus infection," J. Theor. Biol. vol.247, pp.23-35, Jul. 2007.

[6] H. Fang, T. Zhou, "Analysis of an HBV infection dynamics 
model in immune response," Pure and Appl. Math., vol.28, pp.635-540, Oct. 2012.

[7] Y. Ji, L. Min, Y. Zheng, Y. Su, "A viral infection model with periodic immune response and nonlinear CTL response," Math. Comp. Simul., vol. 80, pp. 2309- 2316, Aug.2010.

[8] Q. Xie, D. Huang, S. Zhang, J. Cao, "Analysis of a viral infection model with delayed immune response," Appl. Math. Model. vol. 34, pp. 2388 - 2395, Sept. 2010
[9] A. Fan, K. Wang, "A viral infection model with immune circadian rhythms," Appl. Math. Comp., vol. 215, pp. 3369 3374, Jan. 2010.

[10] R.Gaines, J.Mawhin. Coincidence Degree and Nonlinear Differential Equations, Springer -Verlag, Berlin, 1977. 